\title{
A Governance Model for Managing Lightweight IT
}

\author{
Bendik Bygstad ${ }^{1,2}$ and Jon Iden ${ }^{2}$ \\ ${ }^{1}$ Dept. of Informatics, University of Oslo, Oslo, Norway \\ ${ }^{2}$ Norwegian School of Economics, Bergen, Norway \\ bendikby@ifi.uio.no; jon.iden@nhh.no
}

\begin{abstract}
The widespread introduction of lightweight IT-smartphones, tablets, the Internet of Things, and the growth of third-party app developershas become a challenge for many organizations. Local units and end-users increasingly are acquiring and implementing lightweight IT outside the realm of the IT function. The trend is driven by competent users' need for innovative IT services, enabled by the consumerization of digital technologies. Lightweight IT entails exciting business opportunities; however, guidance for managers on how to deal with this development has been very limited. In this paper, we investigate which IT governance models organizations can apply to manage lightweight IT. The managerial challenge is to balance the innovative potential of lightweight IT with the requirements of good governance. Building on the particular challenges of lightweight IT and the extant literature on end-user computing, we present a framework with four alternative governance models. We evaluate the framework through four e-health case studies.
\end{abstract}

Keywords: Governance, lightweight IT

\section{Introduction}

The unprecedented and global adoption of the smartphone has changed the everyday routines of billions of people; we now use our phone to pay bills, access the company enterprise resource planning (ERP) system, monitor the battery of an electric car, find a restaurant or new partner, and update Facebook. In short, the smartphone has become our key terminal. This trend is challenging the tidy relationship between IT departments and users, in which the IT department provided all the IT services, and the employees used the solutions offered. With the arrival of smartphones and other technologies, this relationship has changed, not only in terms of use-your-own-device but also in terms of knowledge regimes.

Researchers have investigated the arrival of lightweight IT [1, 2], and contrasted it with traditional heavyweight IT. As illustrated in Table 1, lightweight IT supports users' immediate needs, is usually developed outside the IT department, and is characterized by experimentation and innovation. Lightweight IT is driven by competent users' need for innovative IT services, enabled by the consumerization of digital technologies $[1,2]$.

Examples of successful lightweight IT include the following: 
- Mobile apps support citizens in everyday activities, for instance, in traffic routing $[3,4]$ or buying metro tickets.

- Apps support work routines, such as those of service engineers or craftspeople [5].

- Robotic process automation supports white collar work [2].

- Sensors and tablets support welfare technology solutions, often from start-up firms [6].

Although lightweight IT offers a range of possibilities for innovation, it also presents several unresolved challenges, technological as well as managerial. From a technological perspective (and partly as a result of the experimental development attitude), security, privacy, and reliability are obvious challenges in lightweight solutions [7]. As lightweight solutions may need to download and upload corporate data, data integrity issues must be addressed. Moreover, lightweight solutions may easily become new IT silos, because these solutions are not part of a holistic architectural thinking [8].

The responses from IT departments have been mixed but have generally been negative. For instance, bring-your-own-device (BYOD) frequently creates unexpected problems, and parts of the IT industry have tried to stop the lightweight trend, naming it shadow IT [9]. We believe that this approach is futile, mainly because user-driven IT is now an important source of business innovation.

In an equally proactive mode, Gartner suggested bimodal IT $[8,10]$ to deal with old and new IT. Bimodal IT denotes the practice of managing two separate, coherent modes of IT delivery, one focused on stability and the other on agility. The first mode is traditional and sequential, emphasizing safety and accuracy. The second mode is exploratory and nonlinear, emphasizing agility and speed.

Our research is related to these insights, but our perspective is broader. These examples of successful lightweight IT show that we are dealing with a phenomenon that goes beyond the IT department, in that lightweight IT impinges on the whole organization, and the phenomenon goes beyond a single organization, in that we deal with a societal trend. Nevertheless, the trend calls for a managerial strategy; that is, managers need a governance toolbox for managing lightweight IT.

We adopt a governance perspective and discuss who can make decisions about lightweight IT to encourage desirable behavior in the use of IT [11]. We also build on the insights of more recent governance research, which has emphasized that in networks and ecosystems one should aim at orchestration instead of full control [12]. Our research question is, which models are available for reasonable governance of lightweight IT?

\section{Governance Framework for Lightweight IT}

Lightweight IT has emerged for several reasons. First, heavyweight IT has become more professionalized and more successful, but it also suffers from rising costs, increased complexity, and delays. Second, we have witnessed the arrival of cheap commercially available technology, such as smartphones, tablets and the Internet of Things [4]. BYOD has changed users' relationships with the corporate IT department. 
Third, it has been generally recognized [12] that competent users are an important source of innovation. In Table 1, we compare heavyweight and lightweight IT in several dimensions.

Table 1. Heavyweight and lightweight IT [1]

\begin{tabular}{|c|c|c|}
\hline & Heavyweight IT & Lightweight IT \\
\hline Profile & $\begin{array}{l}\text { Back-end: Support documentation } \\
\text { of work }\end{array}$ & $\begin{array}{l}\text { Front-end: Support work } \\
\text { processes }\end{array}$ \\
\hline Systems & Transaction systems & $\begin{array}{l}\text { Process support, apps, business } \\
\text { intelligence }\end{array}$ \\
\hline Technology & $\begin{array}{l}\text { Servers, databases, enterprise bus } \\
\text { technology }\end{array}$ & $\begin{array}{l}\text { Tablets, electronic whiteboards, } \\
\text { smartphones }\end{array}$ \\
\hline IT architecture & Centralized or distributed & $\begin{array}{l}\text { Non-invasive solutions, often } \\
\text { meshwork }\end{array}$ \\
\hline Owner & IT department & Users and vendors \\
\hline $\begin{array}{l}\text { Development } \\
\text { culture }\end{array}$ & $\begin{array}{l}\text { Systematics, standards, quality, } \\
\text { security }\end{array}$ & Innovation, experimentation \\
\hline Problems & $\begin{array}{l}\text { Increasing complexity, rising costs, } \\
\text { delays }\end{array}$ & $\begin{array}{l}\text { Isolated gadgets, security, } \\
\text { privacy }\end{array}$ \\
\hline Discourse & Software engineering & Business innovation \\
\hline
\end{tabular}

The distinguishing feature is not the technology but the digital infrastructure: the network of technology, designers, users, and discourses kept together by a knowledge regime. The profile of heavyweight IT is typically back-office systems, such as ERP systems in production and retail, accounting systems in finance, and electronic patient journal (EPJ) systems in healthcare. Lightweight IT typically supports the immediate needs of the user, providing process support (for instance, when aircraft pilots use tablets for checklists), or simply provides a single piece of information, such as the arrival of the next bus on your smartphone.

The development cultures differ substantially. Heavyweight IT is increasingly being standardized, described as the systematics and quality-oriented ethics of software engineering and IT service management. Conversely, the lightweight culture is more experimental and innovation oriented. The explosive growth of third-party app developers [13] illustrates this trend. In addition, the IT architecture is quite different: Heavyweight IT is based on highly structured solutions designed by enterprise architects, while lightweight IT is usually developed as non-invasive solutions, acting on the presentation layer [2].

The usefulness of lightweight IT vastly increases with a fruitful interplay with heavyweight IT, for instance, when a lightweight app draws on the information resources of heavyweight IT. A typical example is when the metro app on a smartphone accesses the traffic database to show when the next train is coming. Current platforms often consist of a central (heavyweight) service with application program interfaces (APIs) with (lightweight) third-party apps in large ecologies [13, 14]. Dealing with platform structures, therefore, is an important aspect of lightweight governance. 


\subsection{The Framework}

One inspiration for our framework was the work of Alavi, Nelson, and Weiss, who theorized four alternative strategies for dealing with the arrival of PCs and end-user computing in the 1980s [15]. The monopolist strategy is based on the belief that the central IT department should control all IT activities to ensure efficient use of IT resources. In contrast, the laissez-faire strategy allows for experimentation with new technologies and innovation, but growth is unanticipated and unplanned. An alternative is the acceleration strategy, which embraces the opportunities of the new technology and accepts the costs. Finally, the operation-based strategy focuses ongoing management of hardware, software, personnel, and other new IT resources in an effort to maximize the efficient use of these resources. Each strategy requires a mix of technical and organizational mechanisms.

Although the parallel to the introduction of PCs in the 1980s is clear, lightweight IT also presents different challenges. The scope is broader, because lightweight IT includes several technologies, and because IT solutions now permeate organizations and society. In addition, the solutions are not developed by end-users but usually by start-up companies, and the availability of cloud services has made innovators less dependent on central IT operations. In developing our governance framework, we therefore supplement Alavi et al.'s strategies with the special attributes of lightweight IT and research on the platform ecosystem [13]. Some researchers have argued that the diversity of digital innovation requires different innovation networks, such as project, clan, federated, and anarchic networks [16]. Other researchers have found that managers apply ambidextrous resolution strategies to deal with conflicting forces, for example, balancing long- and short-term goals and local versus global needs [17].

In particular, building on Ghazavneh and Henfridson's work, the two dimensions of our framework are resourcing and securing. Resourcing is the process of enhancing innovation and the use of lightweight IT for business purposes [18]. Alternative tactics are, for instance, providing central funding, offering training and skills for lightweight users, providing APIs to heavyweight registers, and establishing organizational mechanisms for support and operation. Securing is the process of controlling the use of lightweight IT, for instance, by developing an acquisition policy with formal request and cost/benefit justifications, limiting the range of lightweight IT hardware and software (creating standards), establishing policies for the central IT function's involvement in lightweight initiatives, and specifying decision rights and accountability for organizational changes and productivity gains. Although each of the two processes in practice may be exercised in varying degrees, we construct our framework in high vs. low ideal types, creating a matrix of the four models, as shown in Fig. 1.

\subsection{Central Control Model}

In the central control model, central (heavyweight) IT management decides which lightweight IT initiatives should be prioritized, based on standard assessment criteria. The focus is on establishing securing mechanisms to control the growth rate of lightweight IT and confine its development to prespecified constraints. The purpose is 
to maintain tight control over all lightweight activities. The advantage is full integration and security, while the disadvantage is little innovation and high costs.

This model is preferred by large vendors, who can develop apps for their heavyweight solutions. For instance, healthcare solutions vendors, such as EPIC and Cerner, offer apps [4], which are fully integrated, both technically and commercially. The central control model is a low-growth strategy and may result in the loss of opportunities for productivity enhancement and organizational innovation. The model could be augmented with a more open model.

\begin{tabular}{|c|c|c|c|}
\hline \multicolumn{3}{|c|}{ Governance models } & Definitions \\
\hline \multirow{4}{*}{$\begin{array}{r}\text { Low } \\
\text { Securing } \\
\text { High }\end{array}$} & \multicolumn{2}{|c|}{ Resourcing } & Resourcing: Enhancing innovation of lightweight IT \\
\hline & \multicolumn{2}{|c|}{ Low High } & Securing: Controlling the use of lightweight IT \\
\hline & $\begin{array}{l}\text { Laissez- } \\
\text { faire }\end{array}$ & $\begin{array}{l}\text { Plat- } \\
\text { form }\end{array}$ & $\begin{array}{l}\text { Laissez-faire: Allowing local implementations, but no support } \\
\text { Central Control: Lightweight IT is subjected under heavyweight }\end{array}$ \\
\hline & $\begin{array}{l}\text { Central } \\
\text { Control }\end{array}$ & $\begin{array}{l}\mathrm{Bi}- \\
\text { modal }\end{array}$ & $\begin{array}{l}\text { Platform: Division of labour between core heavyweight and } 3^{\text {rd }} \text { party } \\
\text { lightweight IT }\end{array}$ \\
\hline & & & $\begin{array}{l}\text { Bimodal: Lightweight solutions are developed by business units, but } \\
\text { set into production under heavyweight regime }\end{array}$ \\
\hline
\end{tabular}

Fig. 1. Four governance models for lightweight IT

\subsection{Bimodal Model}

In this model, a separate light IT management section regulates lightweight IT initiatives, but based on heavyweight technological policies and standards. In line with Gartner's principle for bimodal IT [10], this means that lightweight solutions are developed in separate processes but are subject to the heavyweight regime when integrated and set into production. The advantage of this model is that it leverages the strength of heavyweight and lightweight IT [7]; that is, this model resources and secures the use of lightweight IT. The disadvantage is that the available capacity in the heavyweight IT department and internal budgets will set limits on innovation. Some researchers have also argued that a bimodal IT department can evolve into an arena of internal conflicts [9].

\subsection{Laissez-faire Model}

In the laissez-faire model, heavyweight IT management is not allowed to make decisions about lightweight IT. This strategy allows a free market to emerge. It implies that lightweight solutions are developed and implemented as standalone solutions, for instance, as co-operation between line managers and lightweight or cloud vendors. The advantage is fast innovation and user-oriented solutions, and this strategy will contribute to developing the lightweight segment. The disadvantages are well-known. It is often difficult to scale the solutions, and there are security and privacy issues. Moreover, the laissez-faire approach is sensitive to the availability of internal monetary resources and local users' computing literacy and skills. 
This model is useful when the key purpose is to drive and support innovation. As argued by Lyytinen et al. [16], in order to support digital innovation, one legitimate model is the anarchic innovation network. This does not mean that security and scalability issues can be neglected but that they should be addressed gradually as the solutions grow, not up front.

\subsection{Platform Model}

In the platform model, there is a division of labor between heavyweight and lightweight IT, and central IT management is responsible for encouraging and supporting lightweight IT initiatives. This model is inspired by Apple's and Google's app store solutions. It implies that heavyweight IT becomes a platform for lightweight solutions and offers APIs for third-party innovations. The lightweight solutions compete in the market but must be certified by the platform owner. The advantage is high resourcing; the information resources of heavyweight solutions trigger innovation in the lightweight arena and enable fast innovation at low cost. The disadvantage is that securing lightweight IT is demanding; it requires advanced middleware and mechanisms for dealing with security and privacy. This model is useful for larger ecologies with platforms dominated by a single actor [13, 14].

\section{Research Method and Case Examples}

This paper is based on a longitudinal research project in e-health, which lasted from 2012 to 2016. More than 100 interviews were conducted. The current paper is based on a focused analysis of four cases.

Our theorization was performed in the following steps. We started by assessing issues raised by the lightweight IT phenomenon, conducted a literature review of similar technology shifts, and chose the framework presented in the previous section. Then we chose four cases from the longitudinal research program; the selection criterion was that they presented an opportunity to investigate the managerial challenges of light- and heavyweight IT in a shared context, that is, the healthcare sector.

The four cases were analyzed in detail on three points: (i) the informants' perceptions and use of heavyweight and lightweight IT, (ii) the managerial interventions and the associated results, and (iii) the intervention in terms of the four models.

\subsection{Case 1: Digital Renewal}

The Southeastern Norway Regional Health Authority may be regarded as a government holding company for 11 incorporated hospital organizations, including the largest, Oslo University Hospital. It serves a population of 2.8 million and has 75,000 employees. The long history of decentralized IT decisions had resulted in many systems that worked well in each hospital but also a fragmented portfolio of silo systems. 
As a response, in 2012 the regional authority decided to start an ambitious program called Digital Renewal during the period 2013-2018 with a budget of NOK 6 billion (around EUR 700 million). The main aims were standardizing work processes and technology, operationalized through six sub-programs.

The mega-program was organized and governed in a top-down structure, with a central program board, and a board for each sub-program. The many projects were run by professional project managers, with close supervision and continuous risk management. External consultants regularly produced audits.

The program had absolutely no space for lightweight IT, but local lightweight initiatives frequently popped up in local hospitals. When they requested financial and integration support, they were dismissed with the message that "we need to tidy up the applications mess before we embark on local solutions." However, after increasing pressure from local hospitals and clinics, the regional senior management established in 2016 a regional group for crafting a policy for dealing with lightweight IT.

The managerial strategy employed may be characterized as going from laissezfaire to monopolist. However, the monopolist attitude was challenged by local initiatives, and in 2016, the regional authority searched for a new strategy that might include lightweight IT. A possible solution emerged from one of the hospitals.

\subsection{Case 2: Østfold Hospital}

This was a new hospital in the Southeast Health Region, with 4,800 employees, inaugurated in autumn 2015, and was hailed as the "most IT-savvy hospital in Europe."

In addition to a modern infrastructure, the hospital had developed two new solutions that attracted interest. First, the hospital used whiteboards extensively to support clinical and logistical processes, such as patient carer tracking, nurse calls, critical alarm management, and management of patients waiting for treatment. The whiteboards were placed in most departments and clinics and provided different views (depending on the role and access rights) into processes.

The second solution was extensive use of mobile technology. Nurses, and some doctors, used tablets in their daily ambulatory work with patients. All medical personnel were equipped with special (role-based) smartphones and received emergency calls and other information. Patients were not excluded from the lightweight solutions. On arriving at the hospital, patients checked themselves in and were updated by SMS text messages on their status in the queue.

The Østfold Hospital solution consisted of a combination of heavyweight and various lightweight technologies. This strategy had worked well, and the results were impressive. The strategy employed in this case was bimodal; the lightweight infrastructure of the electronic whiteboards and the mobile technology were produced and implemented by separate teams but were integrated with the heavyweight solutions and subjected to central IT governance. Parts of the solutions were improvised (for instance, the chief information officer [CIO] bought some of the mobile equipment at a local store), and the relationship with the regional data center was consistently strained. 


\subsection{Case 3: St. Hanshaugen Town District}

This case presents a different approach. St. Hanshaugen is a town district in Oslo, with around 25,000 inhabitants. The Home-based Care Section organized a lightweight IT solution for connecting senior citizens with municipal services.

The Norwegian vendor Dignio developed the solution, in close co-operation with the managers of the town district. The solution provides the employee (who might, for instance, be a nurse) with a tablet. Adoption was easy, as the tablet may have a list of (for example) the 30 home residents who are the nurse's responsibility for the day. Each senior individual is linked to the tablet, in different ways: One may suffer from dementia, and his line in the tablet will show a sign if he forgot to lock his door at night. Another may suffer from chronic obstructive lung disease, and she will update (on her own tablet) the status of her health and activities every day, which will be read by the nurse. A third may suffer from heart disease and have a sensor from the hospital, which may trigger an alarm on the nurse's tablet. See Fig. 2.

The solution was developed below the radar in co-operation with a vendor and outside the knowledge of the central municipal IT department. IT security and privacy were not addressed much, as the solutions were improvised. As more town districts in Oslo wanted to build the same solutions, the pressure for a more systematic approach increased.

This is a clear example of a laissez-faire strategy. The solution was initiated by local managers outside the IT governance regime and demonstrated the creative potential of lightweight IT to leverage cheap and innovative process support. This strategy also presented several unresolved problems. This element is addressed in the last case.

\subsection{Case 4: MediCloud}

MediCloud was a small initiative from within HospitalPartner (the IT department of the southeast region) and Invent2 that emerged in 2013, aiming at supporting lightweight applications and connecting them to the established infrastructures of clinical systems.

Medicloud started with only one employee and spent the first year attracting stakeholders and marketing a vision for innovation. The vision was based on breaking up the silos and leveraging lightweight technologies to speed up innovation. During 2014, Medicloud established a position in the e-health community, by being visible in the media (returning 43,000 hits on Google) and building alliances. In 2015, a cloudbased service was offered for third-party vendors of e-health software, and five pilot projects were launched.

Reception in the industry was mixed. The heavyweight vendors were interested but generally negative, and questioned the scalability and security of the solutions. The lightweight vendors were generally positive but were impatient for operative services, not just visions and pilot projects. Medicloud responded that the company was ready to establish a platform, but further growth was dependent on the owners' strategy.

The Medicloud initiative, with remarkably small resources, succeeded in setting innovation on the agenda, attracted the most important stakeholders in the Norwegian 
health sector, and enabled the possible establishment of a lightweight infrastructure within the regional health system. We characterize the MediCloud initiative, although not effective in the short term, as a platform strategy, aiming at exploiting the potential of lightweight IT by connecting it to the information resources of heavyweight systems.

\section{Contribution}

In this paper, we argued that the lightweight IT phenomenon calls for new approaches to governance and requires an understanding of the characteristics of lightweight IT.

The phenomenon has challenged managers, who have acknowledged that it cannot simply be subjected to centralized IT governance but should be dealt with more thoughtfully. Gartner's [10] concept of bimodal IT suggests a partition of the IT department, with one part dealing with traditional IT and the other with new IT. There is also a growing literature on ambidexterity [17], defined as pursuing disparate things in different ways at the same time.

Our governance models are not in conflict with these views, but the models are built on the premise that heavyweight and lightweight IT are different knowledge regimes, which are difficult to combine. To summarize our contribution, we point to three principles for dealing with lightweight IT.

First, we envision a division of labor between heavyweight and lightweight IT, where heavyweight IT should deal with the core systems and registers, and where stability, scaling, and security are paramount, while lightweight IT can take care of the needs of diverse user groups. Three of the four governance models (i.e., all except the central control model) are based on this idea and deal explicitly with the issue.

Second, the key advantage of lightweight IT is innovation; the loosely coupled, non-invasive character of lightweight IT [7] allows for fast innovation of new services, based on the generative relationship [1] between knowledgeable users and IT entrepreneurs. Managing this process is challenging for a predominantly heavyweight IT department, and our models provide an analytical framework for understanding and dealing with the interaction of heavy- and lightweight IT. For instance, the bimodal model requires that lightweight IT is subsumed under the heavyweight regime, while the platform model allows for a much looser coupling.

Third, our framework highlights that governance models are contingent; they are conceptualized as responses to specific challenges and require the deployment of organizational and technical mechanisms. For example, in the health sector a platform for lightweight innovation requires a more sophisticated framework for interaction than an app store for traffic information.

Our framework does not suggest that managers should choose one governance model for all situations. Instead, this framework provides the organization with a larger repertoire of governance mechanisms, allowing managers to manage the interaction of heavyweight and lightweight IT sensibly. The governance models can easily be combined. For instance, an organization may choose a monopolist strategy for supporting the core business processes, while allowing other units to experiment with a more open, laissez-faire approach. Alternatively, if the organization can 
manage the possible tensions of two separate IT units, then the organization should choose a bimodal strategy.

We may also envision a life cycle: first allow free innovation by adopting a laissezfaire strategy and then use a platform for distribution and maintenance. If the lightweight solution is particularly useful, then it can be more tightly integrated with heavyweight IT, and over time, key lightweight solutions can become part of heavyweight IT.

\section{References}

1. Bygstad, B.: Generative innovation: a comparison of lightweight and heavyweight IT. Journal of Information Technology (2016)

2. Lacity, M.C., Willcocks, L.P.: Robotic Process Automation at Telefonica O2. MIS Quarterly Executive 15, 21-35 (2015)

3. Liu, R., Liu, H., Kwak, D., Xiang, Y., Borcea, C., Nath, B., Iftode, L.: Balanced traffic routing: Design, implementation, and evaluation. Ad Hoc Networks 37, 14-28 (2016)

4. Kaur, S.: The revolution of tablet computers and apps. IEEE Consumer Electronics Magazine doi:10.1109/MCE.2012.2223371, (2013)

5. Stieglitz, S., Lattemann, C., Brockmann, T.: Mobile Applications for Knowledge Workers and Field Workers. Mobile Information Systems (2015)

6. Lattanzio, F., Abbatecola, A.M., Bevilacqua, R.: Advanced technology care innovation for older people in Italy: Necessity and opportunity to promote health and wellbeing. Journal of Americal Medical Directors Association 15, 457-466 (2014)

7. L. P. Willcocks, M. C. Lacity, and A. Craig. The IT Function and Robotic Process Automation, London School of Economics, http://eprints.lse.ac.uk/

8. Horlach, B., Drews, P., Schirmer, I.: Bimodal IT: Business-IT Alignment in the Age of Digital Transformation. Multikonferenz Wirtschaftsinformatik (MKWI) (2016)

9. Gyöery, A., Cleven, A., Uebernickel, F., Brenner, W.: Exploring the shadows: IT governance approaches to user-driven innovation. ECIS (2015)

10. Gartner: Bimodal IT: How to Be Digitally Agile Without Making a Mess" (2014)

11. Weill, P., Ross, J.W.: IT Governance Harvard Business School Press, Boston, Mass, (2004)

12. Tiwana, A., Konsynski, B., Venkatraman, N.: Special Issue: Information Technology and Organizational Governance: The IT Governance Cube. Journal of Management Information Systems 30, 7-12 (2013)

13. Tiwana, A.: Platform Ecosystems. Aligning Architecture, Governance and Strategy. Morgan Kaufmann, New York (2014)

14. Eaton, B., Elaluf-Calderwood, S., Sørensen, C., Yoo, Y.: Dynamic structures of control and generativity in digital ecosystem service innovation: the cases of the Apple and Google mobile app stores". Working paper, London School of Economics (2011)

15. Alavi, M., Nelson, R.R., Weiss, I.R.: Strategies for end user computing: An integrative framework. Journal of Management Information Systems, 4(3), 28-49. 4, 28-49 (1987)

16. Lyytinen, K., Yoo, Y., Boland, R.: Digital product innovation within four classes of innovation networks. Information Systems Journal 26, 47-75 (2016)

17. Gregory, R.W., Keil, M., Muntermann, J., Mähring, M.: Paradoxes and the Nature of Ambidexterity in IT Transformation Programs. Information Systems Research 26, 57-80 (2015)

18. Ghazawneh, A., Henfridsson, O.: Balancing Platform Control and External Contribution in Third Party Development: The Boundary Resources Model. Information Systems Journal 23, 173-192 (2013) 